\title{
sciendo CLOUD MANUFACTURING PLATFORM AND ARCHITECTURE DESIGN
}

doi:10.2478/mape-2018-0085

Date of submission of the article to the Editor: 03/2018 Date of acceptance of the article by the Editor: 07/2018

MAPE 2018, volume 1, issue 1, pp. 673-680

\section{Dr Julia Siderska}

Bialystok University of Technology, Poland

\section{Khambi Mubarok}

The University of Auckland, New Zealand

\begin{abstract}
Cloud Manufacturing (CMfg) is an emerging networked manufacturing paradigm and serviceoriented manufacturing model, in which distributed manufacturing resources are made available by providers according to consumers' requirements as on-demand manufacturing services via networks (manufacturing clouds) and cloud manufacturing service platforms.

Considering the concept of cloud manufacturing and its operation principle, the paper designs and introduces new proposal of cloud manufacturing service platform architecture, including the following six layers: physical resources layer, soft resources layer, virtual resources layer, services layer, application layer and service-oriented interface layer. After surveying majority of papers introducing architectures of CMfg service platforms, the paper recommends to map both hard as well as soft resources into cloud services from resource layers to virtual resource layer which highlights the core idea of the concept. The paper discusses also the fundamentals of the CMfg paradigm, introduces three groups of actors that participate in a cloud manufacturing system, as well as indicates briefly a typical hierarchy architecture of cloud manufacturing system.
\end{abstract}

Keywords: cloud manufacturing (CMfg), cloud platform, manufacturing resources and capabilities.

\section{INTRODUCTION}

Rapid global economic integration and the progress of information sharing encourage the manufacturing companies to break through the boundaries of administrative regions and organizations. The companies have been gradually incorporated into the global industrial chain (Wang et al., 2012). In a modern, competitive production environment, manufacturing companies face the challenge of dealing with large amount of data, collaborative usage of them, flexibility of production processes, flexible workstations. In recent years, ICT changed the image of the manufacturing industry. Conventional paper-based technical documents are replaced by data files processed computer-aided design and manufacturing software applications. Nowadays, in the modern manufacturing companies, the production departments, providers and contractors usually are distributed globally (Wang et al., 2017). Also whole production processes, including manufacturing resources and capabilities are places in the different locations.

The key technology enabling integration of distributed manufacturing resources, transforming them into manufacturing services and managing the services centrally is cloud manufacturing. This concept allows multiple users to request services at the same time by submitting their requirement tasks to a cloud manufacturing platform (Liu et al., 2017). CMfg is arising, but very innovative and up-to-date paradigm as it combines the emerged advanced technologies (cloud computing, Internet of Things, virtualization, service-oriented technologies, advanced computing technologies) with existing advanced manufacturing models and technologies (Tao et al., 2011). It is thereby fundamental to integrate decentralized manufacturing resources and establish a collaborative infrastructure among those units. This idea require building the 
networked manufacturing environment to integrate manufacturing resources and applications (Siderska, 2018). Manufacturing resources and know-hows (e.g. software tools, knowledge, applications, equipment, fabrication capabilities, etc.) can be inserted into the cloud and thereby become accessible on demand of presumptive consumers (Siderska and Jadaan, 2018).

Cloud manufacturing paradigm has been expeditiously growing in popularity among researchers over the past few years. The first pioneering attempt to explain and characterize this concept was made by Li (2010) and since then, it attracts more and more attention. The author presented selected definitions of CMfg concept in the review paper (Siderska and Jadaan, 2018). For the purpose of this paper the definition of Adamson was adopted. He considers cloud manufacturing concept as "a network manufacturing model in which locally and globally distributed manufacturing resources for the complete product life-cycle are made available by providers for satisfying consumer demands, and re-centrally organized and controlled as manufacturing cloud services. The model supports unified interaction between service providers and consumers, for trading and usage of configurable resources/services, as well as dynamic and flexible cooperation and collaboration in multi-partner manufacturing missions. Distinct characteristics for the use are that they are scalable, sold on demand, and fully managed by the provider" (Adamson et al., 2017).

The paper is organized as follows: first section discusses the fundamentals and operating principle of the cloud manufacturing concept and indicates three groups of actors participating in a CMfg system. Second section provides the review of architectures and structures of cloud manufacturing platforms, differ in terms of number of layers as well as type of resources inserted in individual layers. It also introduces the proposal of framework of cloud manufacturing platform, combining all input resources and thereby incorporating intangible resources. Conclusions are given in the last section.

\section{CLOUD MANUFACTURING CONCEPT AND PARTICIPANTS}

The fundamental idea of cloud manufacturing concept is to encapsulate manufacturing resources and manufacturing capabilities as well as capacities in networks (manufacturing clouds) and make them available as services, according to the requirements and at the request of consumers, through relative service platforms. In the other words manufacturing resources and capacities are transformed into production services that can be managed and operated in an intelligent and unified way. Cloud manufacturing reflects both the concept of "integration of distributed resources" as well as the concept of "distribution of integrated resources".

The conducted literature review (e.g. Adamson et al, 2017; Tao et al., 2011; Ren et al., 2015) enabled the identification of three groups of actors, participating in a cloud manufacturing system: consumers, providers and operators (brokers) of services. As illustrated in Figure 1, a cloud provider is an entity that provides manufacturing resources and capabilities as cloud services via a cloud platform; a cloud consumer utilizes cloud services via a cloud platform to fulfil demands and a cloud operator operates and manages a cloud platform (Wu et al., 2012). Cloud providers provide manufacturing resources and capabilities as services for consumers. Cloud consumers purchase from provider available (via the cloud) manufacturing services. Operators manage the whole system and services. 


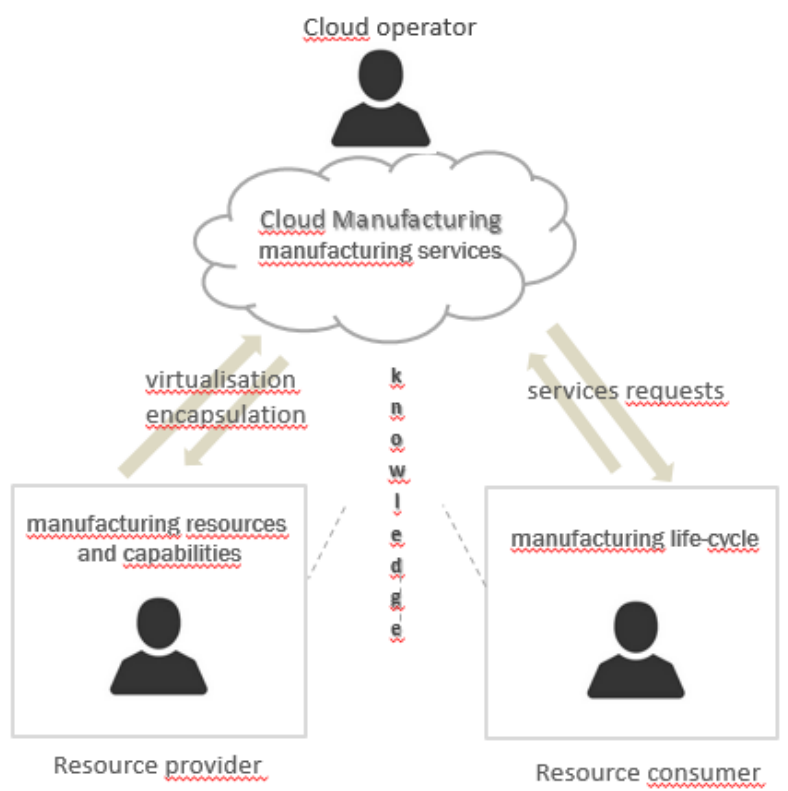

Fig. 1. Participants (actors) of CMfg system

Source: elaborated by the authors based on (Adamson et al. 2017).

Cloud manufacturing is compared with other advanced networked manufacturing concepts, e.g. networked, Internet-based, distributed and grid manufacturing. However, it should be emphasized, that there are some fundamental dissimilarities. Those mentioned networked concepts focus on a single manufacturing task and the integration of distributed resources. They do not have a centralized operation management of the services and embedded access to physical manufacturing equipment, applications and capabilities, which are prerequisites for a stable transaction of manufacturing resource services. Moreover, due to almost lack of coordination between the resource provider and consumer, these concepts are significantly less effective. (Adamson et al., 2017).

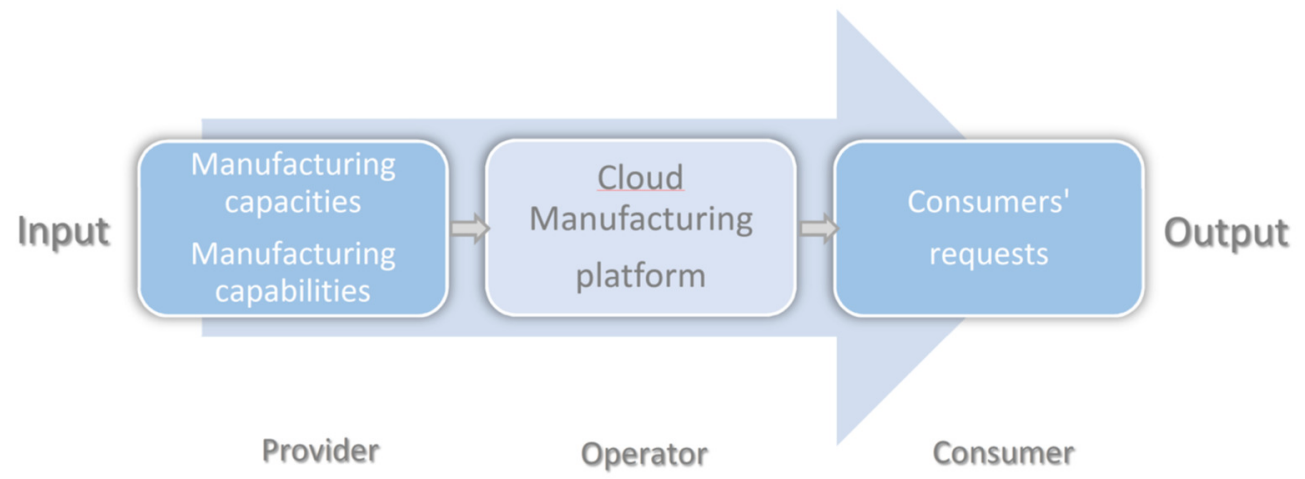

Fig. 2. Cloud manufacturing operating principle

Source: on the basis of (Ning et al. 2011).

According to the transfer of manufacturing resources, the cloud manufacturing system can be divided into three parts: service-oriented input (manufacturing capabilities and capacities), operating platform of manufacturing resources and service-oriented output. The operating principle of the manufacturing cloud is shown in Figure 2 (Ning et al., 2011).

As illustrated in Figure 2, the provider of manufacturing resources inputs the manufacturing resources, including mainly processing equipment, auxiliary software, technical documentation, machining centers, etc. via connector. Then, they are decomposed, grouped and virtualized in virtual resource pool via the cloud manufacturing platform with the use of 
IoT. After requesting services, the virtual resources pool is searched automatically and a rapid response for the request is given. Finally, manufacturing services are output through the interface (Ning et al., 2011).

\section{CLOUD MANUFACTURING ARCHITECTURE}

Most of the researchers indicate manufacturing resources to be shared between three main types of actors participating in cloud manufacturing system. All of manufacturing capabilities require support from the related manufacturing resources, including soft resources (software, engineering knowledge, skills, experience, business networks, etc.) and hard resources, for instance manufacturing equipment, computational resources, monitoring resources, storage, etc. (Wang and $\mathrm{Xu}, 2013$ ). Many researchers propose dedicated system architectures for the development of cloud manufacturing platforms.

As presented in Table 1 the architectures and structures of such platforms differ in terms of number of layers as well as type of resources inserted in individual layers.

Table 1

Architectures of cloud manufacturing systems

\begin{tabular}{|l|c|}
\hline \multicolumn{1}{|c|}{ Proposed layers } & Author(s) \\
\hline $\begin{array}{l}\text { 4 layers: application layer, global service layer, virtual service layer } \\
\text { and manufacturing resource layer }\end{array}$ & Xu (2012) \\
\hline $\begin{array}{l}5 \text { layers: physical resource layer, virtual resource layer, core service } \\
\text { layer, application interface layer and application layer }\end{array}$ & Lv (2012) \\
\hline $\begin{array}{l}5 \text { layers: resource perception layer, virtual pool layer, middleware } \\
\text { layer, toolkit layer and Ul layer }\end{array}$ & Ren et al. (2015) \\
\hline $\begin{array}{l}5 \text { layers: resource layer, perception layer, service layer, middleware } \\
\text { layer and application layer }\end{array}$ & Ning et al. (2011) \\
\hline $\begin{array}{l}6 \text { layers: physical layer, resource-oriented interface layer, virtual } \\
\text { resource layer, core services layer, service-oriented interface layer } \\
\text { and application layer }\end{array}$ & Zhang et al. (2012) \\
\hline $\begin{array}{l}6 \text { layers: resource layer, resource-perception layer, resource virtual } \\
\text { access layer, manufacturing cloud core service layer, transmission } \\
\text { network layer and terminal application layer }\end{array}$ & Wu (2014) \\
\hline $\begin{array}{l}6 \text { layers: physical layer, virtual layer, ontology mapping layer, broker } \\
\text { layer, web portal layer and multitenancy layer }\end{array}$ & Wang et al. (2012) \\
\hline $\begin{array}{l}7 \text { layers: infrastructure layer, manufacturing resources layer, } \\
\text { business unit layer, business cloud and resource cloud, model layer } \\
\text { for cloud manufacturing process, manufacturing cloud layer and } \\
\text { ontology layer }\end{array}$ & \\
\hline $\begin{array}{l}9 \text { layers: resource layer, perception layer, virtualization layer, cloud } \\
\text { service layer (core middleware), application layer, interface layer, } \\
\text { supporting layers: knowledge, security and communication }\end{array}$ & Adamson et al. (2017) \\
\hline $\begin{array}{l}10 \text { layers: resource layer, perception layer, virtual resource layer, } \\
\text { core cloud service layer, application layer, portal layer, enterprise } \\
\text { cooperation application layer, knowledge layer, cloud security layer } \\
\text { and wider Internet layer }\end{array}$ & Huang et al. (2013) \\
\hline $\begin{array}{l}12 \text { layers: manufacture resource layer, integrated operation } \\
\text { environment layer, basic supporting layer, persistent supporting } \\
\text { layer, engine layer, tool layer of cloud service platform, service } \\
\text { component layer, service module layer, business model layer, } \\
\text { transaction layer, enterprise service bus (ESB) layer and user layer }\end{array}$ & \\
\hline
\end{tabular}

$\mathrm{Xu}$ (2012) presented a 4-layer system architecture consisting of application layer, global service layer, virtual service layer and manufacturing resource layer. Lv (2012) proposed a 5layer architecture, including physical resource layer, virtual resource layer, core service layer, application interface layer and application layer. Ren et al. (2015) put forward also a 5-layer system architecture (resource perception layer, virtual pool layer, middleware layer, toolkit layer and UI layer). Similar one was discussed by Zhang et al. (2014): resource layer, perception layer, service layer, middleware layer and application layer. 6-layer architectures 
were presented by: Ning et al. in 2011 (physical layer, resource-oriented interface layer, virtual resource layer, core services layer, service-oriented interface layer and application layer); Zhang et al. (2012): resource layer, resource-perception layer, resource virtual access layer, manufacturing cloud core service layer, transmission network layer and terminal application layer and Wu in 2014: physical layer, virtual layer, ontology mapping layer, broker layer, web portal layer and multitenancy layer. Wang et al. (2012) proposed 7-layer solution consisting of: infrastructure, manufacturing resources, business unit, business cloud and resource cloud, model layer for cloud manufacturing process, manufacturing cloud and ontology layers. More detailed models have up to 12 layers. Adamson et al. (2017) introduced 9-layer architecture, including 6 main layers: resource layer, perception layer, virtualization layer, cloud service layer (core middleware), application layer, interface layer as well as 3 supporting ones: knowledge, security and communication. Very interesting proposal was presented by Huang et al. (2013). They introduced SME-oriented 12-layer service platform and divided its' architecture into optional and required layers. Among required layers the following were indicated: manufacture resource layer, integrated operation environment layer, basic supporting layer, persistent supporting layer, engine layer, business model layer, transaction layer, enterprise service bus (ESB) layer and user layer. The authors indicated tool layer of cloud service platform, service component layer as service module layer as optional.

Although the proposed architecture solutions have slightly different naming, content and system structures, almost all of them share some similar elements, such as resource virtualization and cloud service composition. To sum up the proposed in the literature cloud manufacturing concept architectures, Adamson et al. (2017) presented the proposal of quite typical one, consisting of the six main layers as follows: resource layer, perception layer, virtualization layer, cloud service layer (core middleware), application layer, interface layer and three supporting layers: knowledge layer, security layer and communication layer. However, his concept excludes intangible assets of the company.

It should be also emphasized that most of researchers indicate two basic types of manufacturing resource: hard resources and soft resources. A hard resources could be considered as a manufacturing cells as well as IT hardware, equipment, materials, buildings, machines, etc. Soft resources include software, knowledge, information, data or other intellectual units. In author's opinion it is necessary to consider also other, significant intangible assets, namely the human capital of each individual employee and the social capital of the workers of the whole company. Human capital is derived from competences, tacit knowledge, experiences, skills, education, training, etc. of workers considered as discrete individuals. Social capital is composed of formal and/or informal relations among workers, teams, organizational units, etc. The skills, experience, talent of individual people involved in cloud manufacturing system, as well as trust and collaboration of workers in company are the most significant and valuable resources of all enterprises operating in the manufacturing industry (Siderska, 2018).

Even though the researchers recognize both hard and abovementioned soft resource as equally significant assets of each company, they do not consider the possibilities to insert them into manufacturing cloud and make them accessible as services on consumers' demands. As shows Figure 3, the author proposed the architecture of cloud manufacturing platform, involving soft resources layer. 


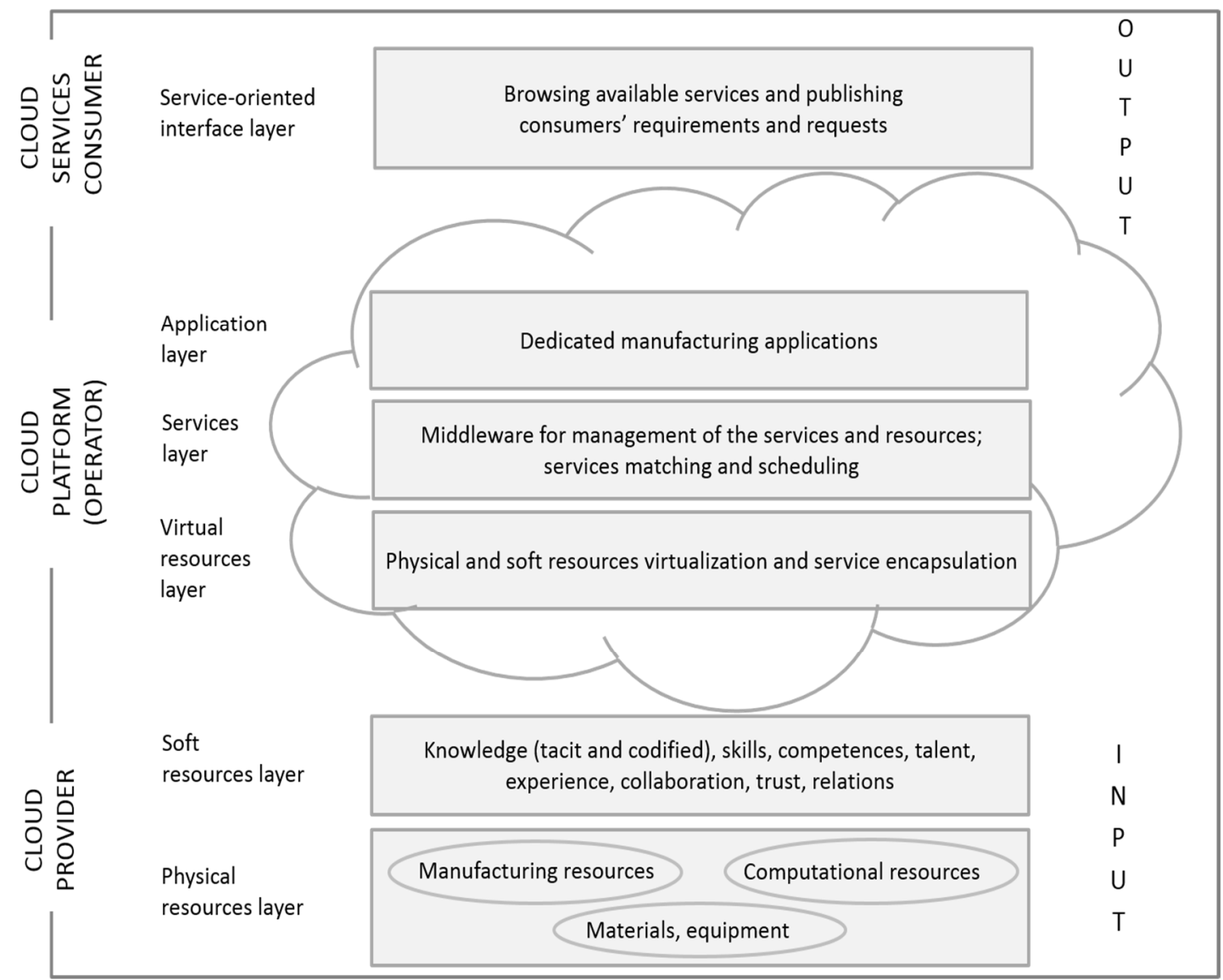

Fig. 3. CMfg platform architecture

Proposed cloud manufacturing platform architecture consists of six layers: physical resources layer, soft resources layer, virtual resources layer, services layer, application layer and service-oriented interface layer. Provider collects manufacturing resources and capabilities into cloud and make them accessible on demands and requests of consumers. Provider's task should also be to encapsulate and virtualize soft resources. Among all of them the following should be mentioned: skills, competences, talent, experience of manufacturing workers. Moreover, soft resources layer should also include the ability of collaboration, favorable relations and trust among employees. Such gathered resources compose together, according to Figure 2, service-oriented input of the cloud.

Cloud manufacturing platform manages a shared pool of manufacturing resources and capabilities over a network, offering integrated IT-based infrastructure and tools for providers and consumers. A cloud manufacturing platform should allow a variety of manufacturing resources to be connected together. Moreover, the platform should have the ability of identifying key information of the connected resources and transforming real manufacturing resources into virtual resources. Resource virtualization is the process of mapping resources from a real manufacturing to logical ones (Ren, 2015). Operator manages and operates a cloud platform as well as utilizes cloud services via a cloud platform to fulfil consumers' demands. Resources are decomposed, grouped and virtualized in virtual resource pool via the cloud manufacturing platform. After requests of services, the virtual resources pool is searched automatically and a rapid response for the request is given. Finally, manufacturing services are output through the service-oriented interface layer.

Cloud services have a life cycle, thus it is necessary to support cloud service publishing, intelligent matching and composition (Tao et al., 2013). 


\section{CONCLUSIONS}

The ability to encapsulate and virtualize manufacturing resources, capabilities and capacities is one of the key virtues of cloud manufacturing paradigm. However, this ability should refer to all manufacturing resources, even those relating to human factor.

Based on conducted literature review and considering the fundamentals of cloud manufacturing concept and its operation principle, the author designed the cloud manufacturing service platform architecture, composed of the required six layers: physical resources layer, soft resources layer, virtual resources layer, services layer, application layer and service-oriented interface layer. The author recommended to encapsulate both hard as well as soft resources into cloud services from resource layers to virtual resource layer.

Moreover, the paper introduces intangible resources to be inserted into manufacturing cloud and made accessible to fulfil demands and requests of presumptive consumers. Among others, they are: competences, tacit knowledge, experiences, skills, education, training, etc. of workers considered as discrete individuals. The following assets are also significant: relations among workers, teams, organizational units, trust and collaboration of workers in company. Proposed soft resources layer allows to consider human factor as manufacturing resources and encapsulate them into the clouds.

Although the vision of cloud manufacturing development is promising, the research within this area is still in the initial stage and thus important challenges exist. Several significant technical issues should be solved by researchers and inside the companies. Among others, the following should be mentioned: the possibilities of bringing a diverse base of resources and capabilities into the cloud as service; order decomposition into tasks; the selection of provider to perform them; the managing and scheduling of the whole manufacturing process; collaboration between cloud manufacturing applications; security of data, business know-how and intellectual properties.

\section{ACKNOWLEDGMENTS}

The research were conducted within S/WZ/1/2014 project and were financed from Ministry of Science and Higher Education funds.

\section{REFERENCE}

Adamson, G., Lihui, W., Holm, M. and Moore, P. 2017. Cloud manufacturing - a critical review of recent development and future trends. International Journal of Computer Integrated Manufacturing, 30 (4-5), pp. 347-380.

Gudanowska, A.E. 2017. Transformation Towards Industry 4.0 - Identification of Research Trends and Aspect of Necessary Competences in the Light of Selected Publications. Research in Logistics and Production, 7(5), pp. 431-441.

Huang, B., Li, Ch., Yin, C., Zhao and X.P. 2013. Cloud manufacturing service platform for small- and medium-sized enterprises. International Journal of Advanced Manufacturing Technology, 65 (912), pp. 1261-1272.

Li, B.H., Zhang, L., Wang, S., Tao, F., Cao, J., Jiang, X. and Song, X. 2010. Cloud Manufacturing: A New Service-Oriented Networked Manufacturing Model. Computer-Integrated Manufacturing Systems, $16(1)$, pp. 1-8.

Liu, Y.K. Xu, X., Zhang, L., Wang, L. and Zhong, R.Y. 2017. Workload-based multi-task scheduling in cloud manufacturing. Robotics and Computer-integrated manufacturing, 45, pp. 3-20.

Lv, B. 2012. A Multi-View Model Study for the Architecture of Cloud Manufacturing. Proceedings on the Third IEEE International Conference on Digital Manufacturing and Automation (ICDMA). Guilin, pp. 93-97.

Ning, F., Zhou, W., Zhang, F., Yin, Q. and Ni, X. 2011. The Architecture of Cloud Manufacturing and Its Key Technologies Research. Proceedings of IEEE International Conference on Cloud Computing and Intelligence Systems (CCIS). Beijing, pp. 259-263.

Ren, L., Zhang, L., Zhang, Y., Tao, F. and Luo, Y. 2011. Resource virtualization in cloud manufacturing. Computer-Integrated Manufacturing Systems CIMS, 17(3), pp. 511-518.

Ren, L., Zhang, L., Tao, F., Zhao, Ch., Chai, X. and Zhao, X. 2015. Cloud manufacturing: from concept to practice. Enterprise Information Systems, 9(2), pp. 186-209.

Siderska, J. and Jadaan, K.S. 2018. Cloud manufacturing: a service-oriented manufacturing paradigm. A review paper. Engineering Management in Production and Services, 10(1), pp. 22-31. 
Siderska, J. 2018. Cloud Manufacturing - the Adoption of Virtual Production Line to Soft Resources Analysis. The 8th International Conference of Engineering. Project and Production Management: EPPM 2017 Proceedings. Lecture Notes in Mechanical Engineering, pp. 225-233.

Tao, F., Zhang, L., Venkatesh, V.C., Luo, Y. and Cheng, Y. 2011. Cloud manufacturing: A computing and service-oriented manufacturing model. Proceedings of the Institution of Mechanical Engineers Part B Journal of Engineering Manufacture, pp. 1969-1976.

Tao, F., LaiLi, Y., Xu, L. and Zhang, L. 2013. FC-PACO-RM: A Parallel Method for Service Composition Optimal-Selection in Cloud Manufacturing System. IEEE Transactions on Industrial Informatics, 9(4), pp. 2023-2033.

Wang, M., Zhou, J. and Jing, S. 2012. Cloud Manufacturing: Needs, Concept and Architecture. Proceedings of the 2012 IEEE 16th International Conference on Computer Supported Cooperative Work in Design, Wuhan, pp. 321-327.

Wang, X.V., and Xu, X. 2013. An interoperable solution for Cloud manufacturing. Robotics and Computer-Integrated Manufacturing, 29(4), pp. 232-247.

Wang, X.V., Givehchi, M. and Wang, L. 2017. Manufacturing system on the cloud: a case study on cloudbased process planning. Procedia CIRP, 63, pp. 39-45.

$\mathrm{Xu}, \mathrm{X}$. 2012. From cloud computing to cloud manufacturing. Robotics and Computer-Integrated Manufacturing, 28, pp. 75-86.

Zhang, L., Luo Y., Tao, F., Li, B., Ren, L., Zhang, X., Guo, H., Cheng, Y., Hu, A. and Liu, Y. 2014. Cloud manufacturing: a new manufacturing paradigm. Enterprise Information System, 8(2), pp. 167-187. 